\title{
Effect of Warm Rolling on the Corrosion and Mechanical Properties of UNS S32205 Duplex Stainless Steel
}

\author{
Dalila Chaves Sicupira ${ }^{a *}$, Raphael França Assumpção ${ }^{a}$, Daniela Barçante Perasolia ${ }^{\circ}$ Davi Silva Alves ${ }^{b}$, \\ Aline Oliveira Vasconcelos Ferreira ${ }^{b}$, Dagoberto Brandão Santos ${ }^{b}$ \\ ${ }^{a}$ Departamento de Química, Universidade Federal de Ouro Preto, Campus Morro do Cruzeiro, \\ 35400-000, Ouro Preto, MG, Brasil \\ ${ }^{b}$ Departamento de Engenharia Metalúrgica e de Materiais, Universidade Federal de Minas Gerais, \\ 31270-901, Belo Horizonte, MG, Brasil
}

Received: July 04, 2018; Revised: December 14, 2018; Accepted: June 24, 2019

\begin{abstract}
Duplex stainless steel (DSS) has been considered as an excellent alternative for applications where high corrosion resistance and high mechanical strength are required. Therefore, microstructure and properties of DSS remain topics of much interest. For this purpose, the effect of warm-rolling was studied in a duplex stainless steel. The focus of this work was 2205 which is one of the most useful type of DSS. Although evolution of microstructure, texture and tensile properties during warm rolling of DDS have been reported, there is no study on the effect of warm rolling on corrosion resistance of 2205 DSS. In this context, the objective of this work is to evaluate microstructure, texture and mechanical and corrosion properties of UNS S32205 DSS after warm rolling. The duplex stainless steel was warm-rolled at $600^{\circ} \mathrm{C}$ up to 60 and $80 \%$ thickness reduction and submitted to electrochemical tests. The electrochemical behaviour of warm-rolled 2205 in the chlorine ion environment was evaluated using cyclic potentiodynamic polarization (CPP) and electrochemical impedance spectroscopy (EIS). The samples exhibited an excellent corrosion resistance in $3.5 \% \mathrm{NaCl}$ solution. The study showed that the thermomechanical treatment used favoured the formation of the passive film and led to a greater polarization resistance. This behaviour is consistent with the pits density observed by scanning electron microscopy (SEM) and the crystallographic microtexture of the steel.
\end{abstract}

Keywords: Duplex stainless steel, Thermomechanical treatment, Corrosion resistance, Mechanical properties.

\section{Introduction}

Duplex stainless steels (DSS) is a class of stainless steels that combine corrosion and mechanical properties ${ }^{1,2}$. The number of applications for DSS increases and new alloys are continuously developed due to the volatility of the Ni price. The nickel content can be partially replaced by manganese and nitrogen in these alloys ${ }^{3,4}$. The microstructure comprised of approximately equal amounts of austenite $(\gamma)$ and ferrite $(\alpha)$ phases and the lack of secondary phases such as $\sigma, \mathrm{M}_{23} \mathrm{C}_{6}$ and $\mathrm{Cr}_{2} \mathrm{~N}$ provides the advantage of mechanical properties along with corrosion resistance as compared to the usual single-phase stainless steels ${ }^{5,6,7}$.

Alloying elements such as $\mathrm{Cr}, \mathrm{Mo}, \mathrm{Ni}$ and $\mathrm{N}$ lead to the high corrosion resistance observed in the DSS. But, their corrosion resistance is affected by thermomechanical processing since they cause changes in the microstructure ${ }^{8,9}$. During this thermomechanical processing, such as warm rolling, this alloy is exposed to moderate temperatures causing microstructural changes ${ }^{5}$. Although the rolling process may be carried out at temperatures above the half of the melting point of the metal, called hot rolling, or below

*email: dalila@ufop.edu.br that temperature, in which case cold rolling is concerned, there is a temperature range, starting below and ending above the dividing line between hot and cold rolling, within which the process is called warm rolling ${ }^{10}$. These processes lead to mechanical and metallurgical changes in the sample, which are not possible to achieve in cold or hot process ${ }^{10}$.

From the commercial point of view, warm rolling is considered particularly beneficial in the fabrication of new products and in the reduction of production costs of hot rolled strips ${ }^{11}$. The effect of the warm rolling on DSS is interesting, especially since ferrite and austenite may exhibit different softening behaviour during deformation. It has been discussed that there is not a dependency between the two phases deformation and the evolution of the microstructure. And, also, texture can be obtained from the behaviour of monophasic materials ${ }^{5,11}$. However, the process of texture formation is different depending on the initial crystallographic orientation distribution ${ }^{12}$. The evolution of microstructure and texture during deformation and recrystallization in single-phase steels has received more attention than in DSS ${ }^{11}$. And, most of the prior studies on deformation behaviour of DSS steels have focused on hot-deformation following by cold-rolling and subsequent annealing or aging ${ }^{13-15}$. 
Ahmed et al. ${ }^{5}$ studied the tensile properties of a warm rolled and annealed DSS. Their results showed that the warm rolling lead to ultrahigh strength $(1 \mathrm{GPa})$ and the posterior annealing caused improvement in ductility at the expense of strength.

Jinlong et al. ${ }^{16}$ evaluated the effect of pre-deformation on the corrosion resistance of 2205 DSS. The results showed that increasing of strain led to the increase of dislocation density in ferritic and austenitic phases and more dislocations associated with chloride ions promotes autocatalytic reaction causing the breakdown of the passive film formed on 2205 DSS.

The pitting susceptibility has been also associated to steel texture (crystallographic grain orientation). Venegas et al. ${ }^{17}$ founded for high strength low alloy steel the highest pitting corrosion resistance at $\{110\} N D$ texture fibre. The resistance of the $\{\mathrm{hkl}\} \mathrm{ND}$ texture fibres to pitting corrosion in their studied steel was first assumed and then experimentally observed to decreases in the following order: $\{110\} N D ;\{200\} N D>\{222\}$ ND $>\{112\}$ ND $>$ Random. Ravi Kumar et al. ${ }^{18}$ reported the adverse effect of the rolling tensile residual stress on passivation and prepassivation characteristics of an austenitic stainless steel. According to them, this effect appears to be nullified by the beneficial crystallographic orientation at higher reductions.

As discussed above, microstructure, texture and properties of duplex steels remain topics of much interest. Although evolution of microstructure, texture and tensile properties during warm rolling of DSS has been reported, there is no study on the effect of warm rolling on corrosion resistance of 2205 DSS. In this context, the objective of this work is to evaluate microstructure, texture and mechanical and corrosion properties of UNS S32205 DSS after warm rolling.

\section{Materials and Methods}

The material used in this study was warm-rolled at $600^{\circ} \mathrm{C}$ up to reductions of 60 and $80 \%$ in thickness. The UNS S32205 steel was supplied in the form of hot rolled small strips with $5.5 \mathrm{~mm}$ thick, $150 \mathrm{~mm}$ long and 100 mm wide. The steel composition is showed in Table 1. The warm rolling was performed in a Fröhling laboratory rolling mill using samples previously soaked for $30 \mathrm{~min}$ at $600^{\circ} \mathrm{C}$. The process was performed up to a thickness of $2.20 \mathrm{~mm}$ in nine passes $(\varepsilon=0.60)$ or $1.15 \mathrm{~mm}$ in sixteen passes $(\varepsilon=0.80)$. After each pass, a necessary reheating for $15 \mathrm{~min}$ was applied to ensure the plate temperature of $600^{\circ} \mathrm{C}$ before the next rolling step. Following the last pass, the strip was cooled to room temperature in air. The optical micrographs and those obtained with SEM of as received (AR), 60\% warm rolled (WR 60\%) and $80 \%$ warm rolled (WR 80\%) samples were obtained after electrolytic etching with oxalic acid or Behara etchant.
The preparation of the samples for transmission electron microscopy (TEM) consisted of cutting, mechanical grounding to the thickness around $200 \mu \mathrm{m}$ and final reduction to a thickness of 50-70 $\mu \mathrm{m}$ with grid 1200 emery paper. Then, these samples were polished with $1 \mu \mathrm{m}$ diamond paste and punched on the disk puncher device, obtaining disks of 3 $\mathrm{mm}$ in diameter. Thin foils were prepared from thick discs thinned to 50-70 $\mu \mathrm{m}$ twin-jet-polishing in a solution of 5\% perchloric acid and $95 \%$ methanol between $248 \mathrm{~K}$ and 258 $\mathrm{K}\left(-30^{\circ} \mathrm{C}\right.$ and $\left.-20^{\circ} \mathrm{C}\right)$ at a $40 \mathrm{~V}$ of etching potential using a Struers Tenupol Electropolisher device.

The samples were characterized by scanning electron microscopy (SEM), electron backscattering diffraction (EBSD) and X-ray diffraction (XRD). Samples were ground and polished until $1 \mu \mathrm{m}$ diamond paste. The EBSD samples were automatically polished in colloidal silica of $0.04 \mu \mathrm{m}$ particle size for $90 \mathrm{~min}$. The samples were scanned at a step size of $0.02^{\circ} \mathrm{s}^{-1}$ and a $2 \theta$ angle ranging from $20^{\circ}$ to $110^{\circ}$ in an $\mathrm{X}$-ray diffraction instrument (Pan Analytical Empiryan). The microtexture analysis by EBSD was quantitatively calculated by the TSL-OIM ${ }^{\mathrm{TM}}$ software. The microtexture of austenite and ferrite was carried out using constant section of orientation distribution function (ODF) in the $\varphi_{2}=45^{\circ}$ of the Euler space.

A Future Tech FM700 Vickers microhardness instrument loaded to $4.9 \mathrm{~N}$ for $10 \mathrm{~s}$ was used to measure microhardness. The average result was calculated from 20 indentations. Tensile test was performed in an Instron machine model 5582, using the software Blue Hill for data acquisition at room temperature with a strain rate of $10^{-3} \mathrm{~s}^{-1}$ (cross head speed of $1 \mathrm{~mm} \cdot \mathrm{min}^{-1}$ ). The specimens were machined according to sub-size dimensions of the gage section of $25.4 \times 6.25 \times 1.15$ or $2.2 \mathrm{~mm}$, depending on the warm rolling reduction, 60 or $80 \%$, respectively.

The electrochemical measurements were performed using cyclic potentiodynamic polarization (CPP) and electrochemical impedance spectroscopy (EIS) in 3.5\% $\mathrm{NaCl}$ solution at room temperature. A conventional three electrode cell with platinum plate as an auxiliary electrode and $\mathrm{Ag} / \mathrm{AgCl}$ electrode as the reference electrode was used. The equipment was a Potentiostat Autolab PGSTAT302N. Samples were cut out and embedded in acrylic resin. The exposed area was of $1 \mathrm{~cm}^{2}$. Before each experiment, the working electrodes were ground using 100, 240, 320, 400, 600 mesh, degreased with detergent, alcohol, washed in water and stored in a desiccator.

EIS tests were carried out at open circuit potential (OCP) and a sinusoidal signal was applied in the frequency range of $100 \mathrm{kHz}-5 \mathrm{mHz}$ with amplitude of $10 \mathrm{mV}$ and 10 points per decade. The acquired impedance spectra are presented as Nyquist plots and interpreted in terms of equivalent electrical circuits using ZView program (Scribner Assoc.)

Table 1. Chemical composition (\% by mass) of stainless steel UNS S32205

\begin{tabular}{llllllllll}
\hline Element & $\mathrm{C}$ & $\mathrm{Mn}$ & $\mathrm{Si}$ & $\mathrm{Cr}$ & $\mathrm{Ni}$ & $\mathrm{Mo}$ & $\mathrm{N}$ & $\mathrm{P}$ & $\mathrm{S}$ \\
\hline Content & 0.026 & 1.83 & 0.25 & 22.43 & 5.44 & 3.04 & 0.15 & 0.03 & 0.0002 \\
\hline
\end{tabular}


to fit the experimental data. Polarization test was initiated after $60 \mathrm{~min}$ of OCP stabilization. A scan rate in the anodic direction of $0.167 \mathrm{mV} / \mathrm{s}$ was applied until a current density of $1 \mathrm{~mA} / \mathrm{cm}^{2}$ was reached. At this point the scan was reverted to cathodic direction. Electrochemical tests were performed in triplicate. The pit morphology, after the electrochemical experiments, was examined by SEM.

\section{Results and Discussion}

Figure 1 illustrates the optical micrographs of etched samples of AR and WR $60 \%$ and WR $80 \%$, and Figure 2 presents SEM micrographs of these conditions. Lamellae of ferrite and austenite are a noticeable feature in the deformed structures. These lamellae appear as approximately parallel lines within the grains from the early stages of deformation. The plastic deformation of austenitic phase evolved by dislocation slip and deformation twinning, while the plastic deformation of ferritic phase occurred mainly via dislocation activities ${ }^{4,19}$.

The refinement of the microstructure, as well as, the alignment of the ferrite and austenite bands according to rolling direction, can be seen in Figure 2a and b. In Figure 2c it is also possible to notice that bands or lamellas of the phases $(\alpha+\gamma)$ became wavy due to the intense warm deformation imposed to the steel.
At the same time, there was a deep substructure modification, as will be seen in the transmission electron microscopy.

The TEM micrographs obtained correspond to observations made in the rolling plane, but due to the sequential gridding on both faces, the section examined corresponded to approximately half the strip thickness. Figure 3 a shows the presence of narrow slip band ${ }^{20-22}$ in the austenite (region on the right side in the micrograph, pointed by arrows) and dense dislocation walls (DDW). Figure $3 \mathrm{~b}$ shows subgrains in the ferrite and annealing twin in austenite. Figure $3 \mathrm{c}$ shows planar slip bands in austenite and respective electron diffraction pattern, Figure 3d. Figures $3 \mathrm{e}$ and $3 \mathrm{f}$ illustrate the grain size of duplex microstructure and discrete dislocations loops and arrangements in ferrite.

Cells dislocations and planar slip structure was observed in the steel after hot rolling, see Figure $3^{20,22}$. In contrast, a structure of dislocations bands with walls of high density of dislocations (HDDW) and defined cells blocks were found in the austenite and ferrite phases after warm rolling at $600^{\circ} \mathrm{C}$, Figures 4-6. These observations are consistent with those found in austenitic stainless steels subjected to the dynamic aging process (DSA), in which the dislocations structure changes from a cellular structure at room temperature to a planar at 573 and $873 \mathrm{~K}^{23}$.

The texture mechanism involves relative rotation between different parts of a grain for different final orientations due to differences in the selection of slip systems $5,24,25$.
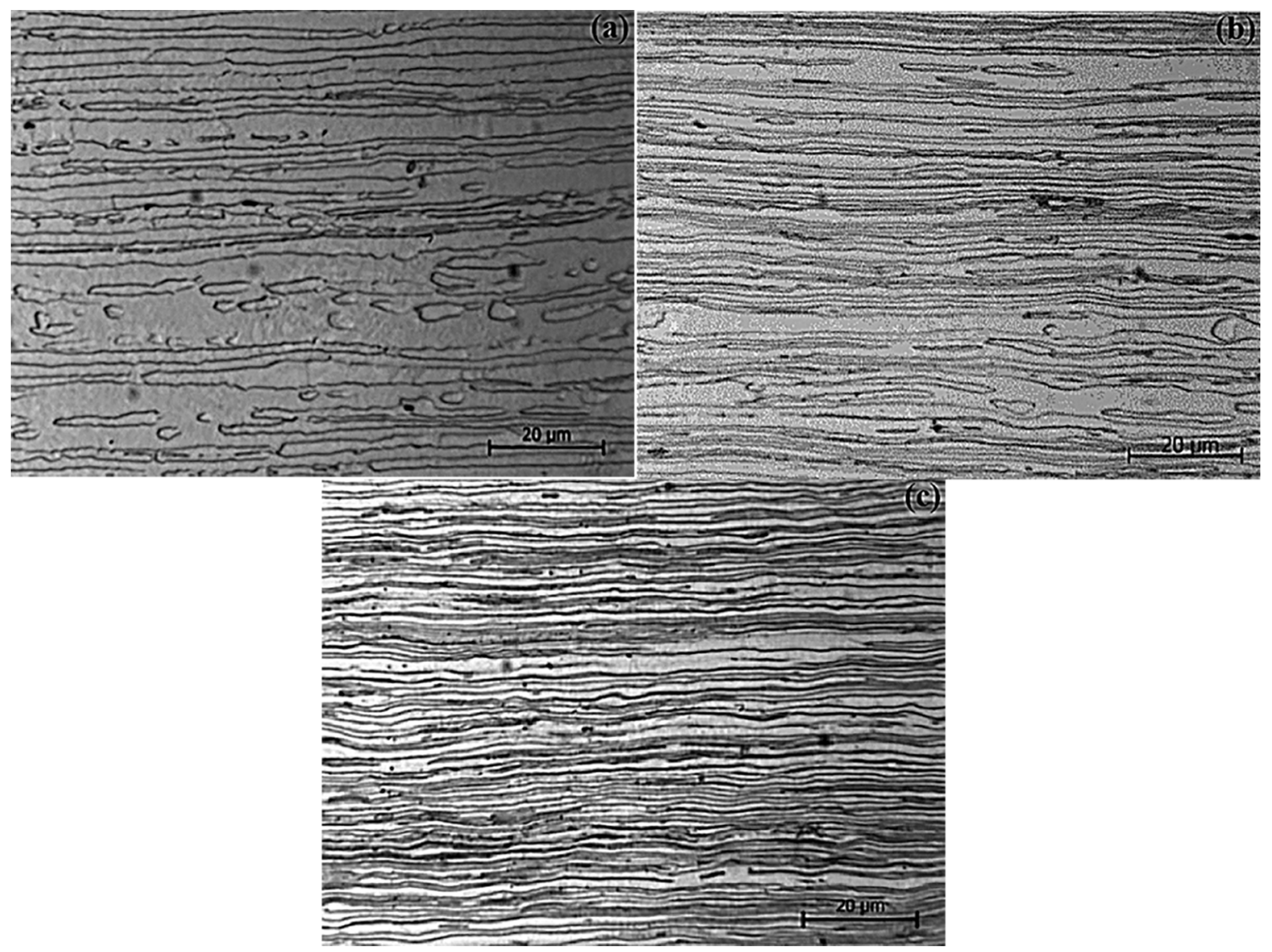

Figure 1. Optical micrographs of the samples (a) AR, (b) WR 60\% and (c) WR 80\%. Electrolytic etch with oxalic acid. 


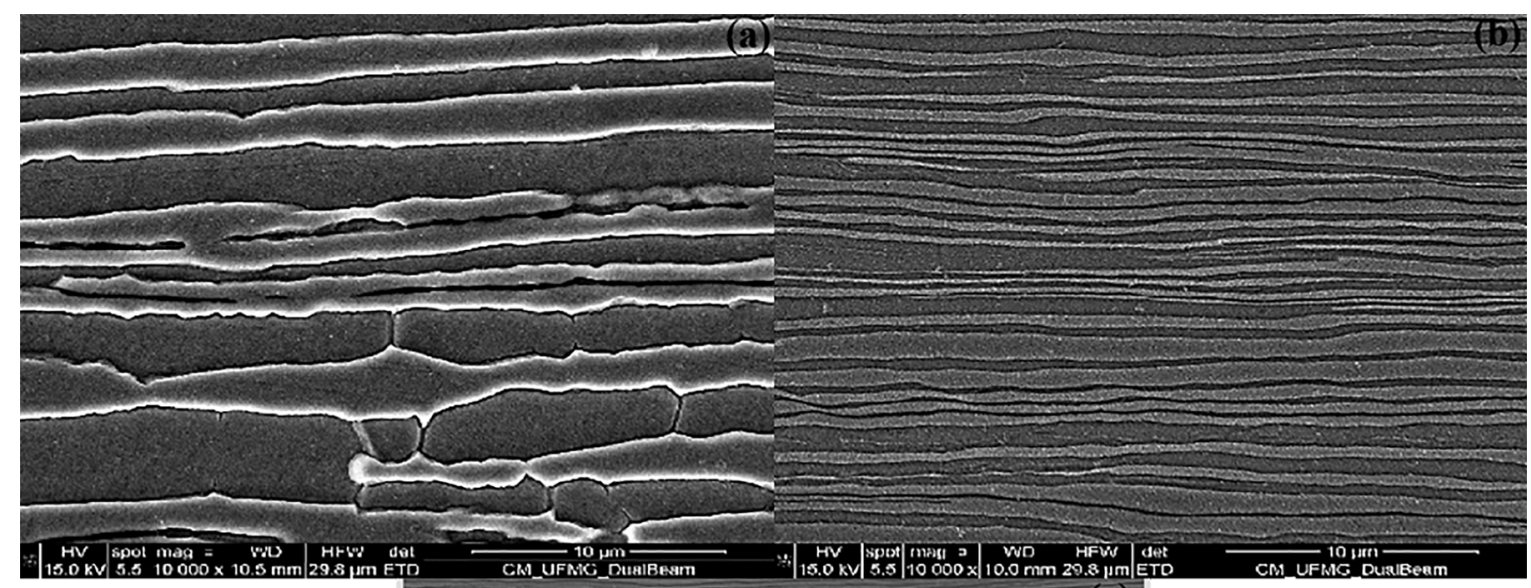

(c)

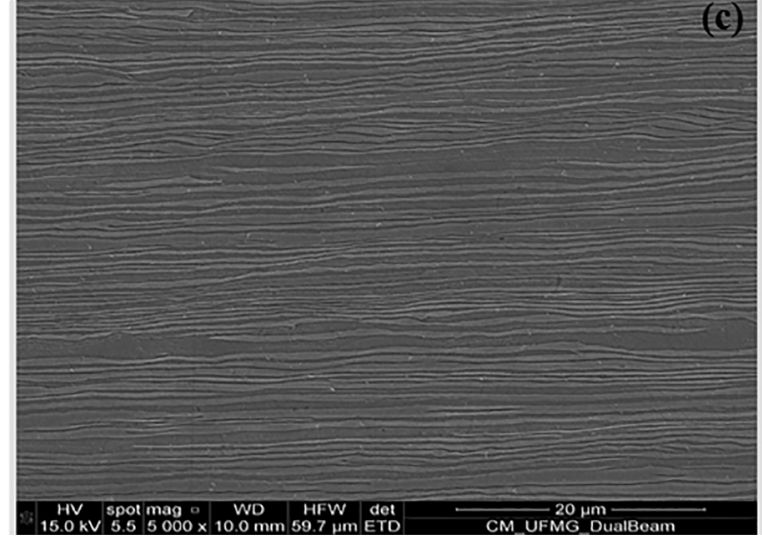

Figure 2. SEM micrographs of the samples (a) AR, (b) WR $60 \%$ and (c) WR $80 \%$. Etched with Behara etchant.

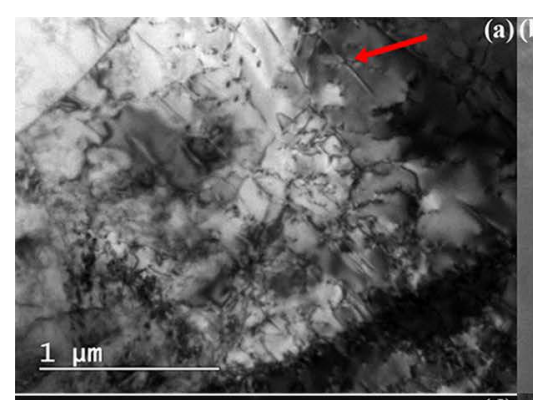

(d)

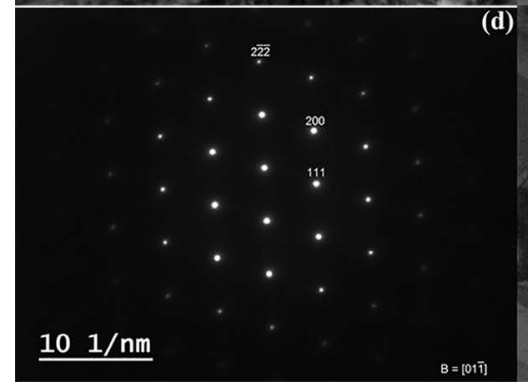

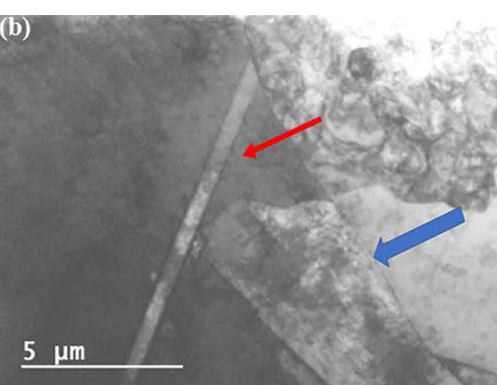
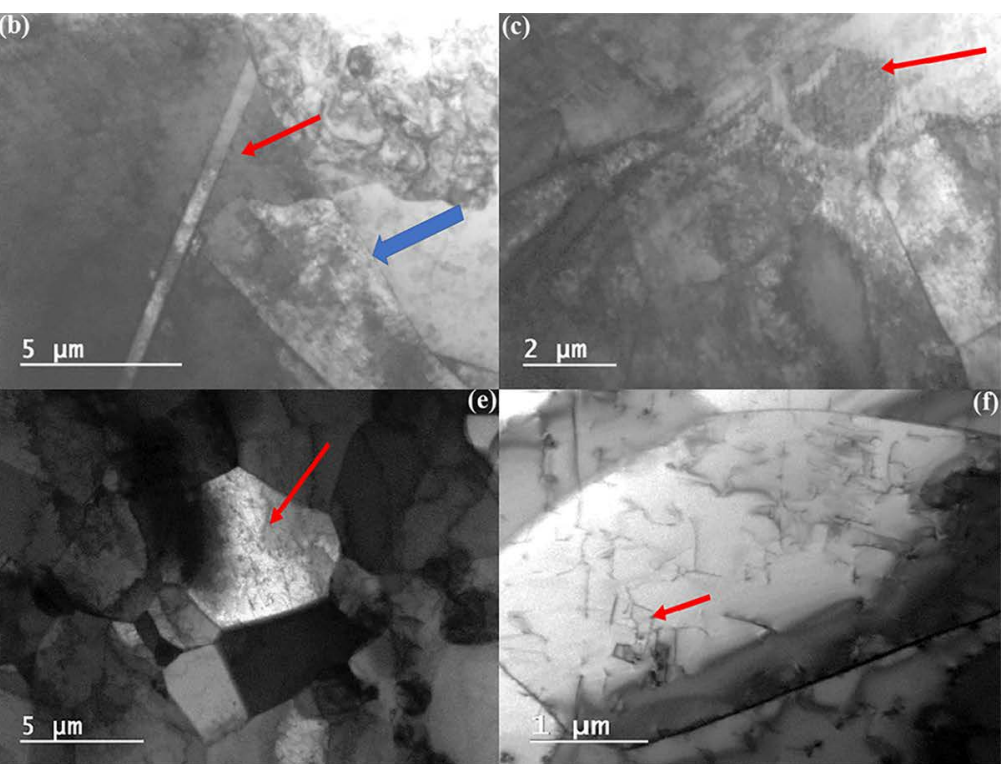

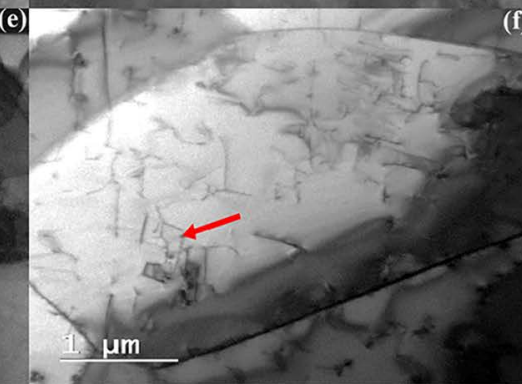

Figure 3. Bright field TEM images of the hot-rolled microstructure, as-received sample, showing (a) austenite and ferrite with subgrains, (b) high angle grain boundary between austenite and ferrite (blue arrow), annealing twin in austenite (red arrow), (c) planar slip in the austenite and some dislocations walls in the ferrite, (d) diffraction pattern of the austenite, (e) austenite and ferrite microstructure, annealing twin and incipient DDW formation (red arrow), (f) discrete dislocations loops in ferrite. 


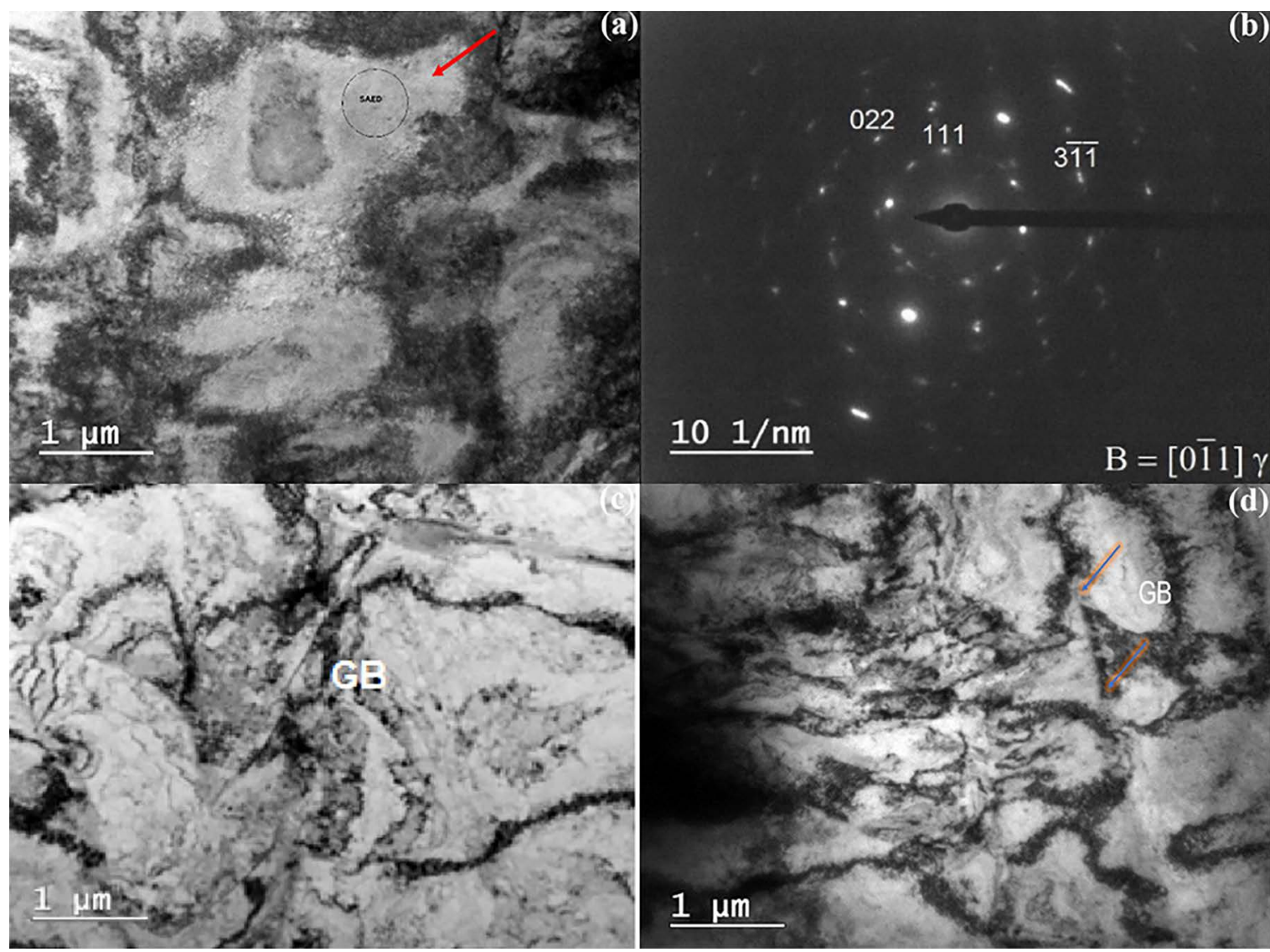

Figure 4. (a-d) Micrographs obtained in bright field in TEM corresponding to microstructure of the WR $60 \%$ at $600^{\circ} \mathrm{C}$. (a,c,d) Formation of cell blocks along with dense dislocations walls, (b) electron diffraction pattern with respect to austenite in the central region of the micrograph in (a), indicated by arrow. (d) tangles of dislocations with dense dislocations walls in ferrite and austenite.

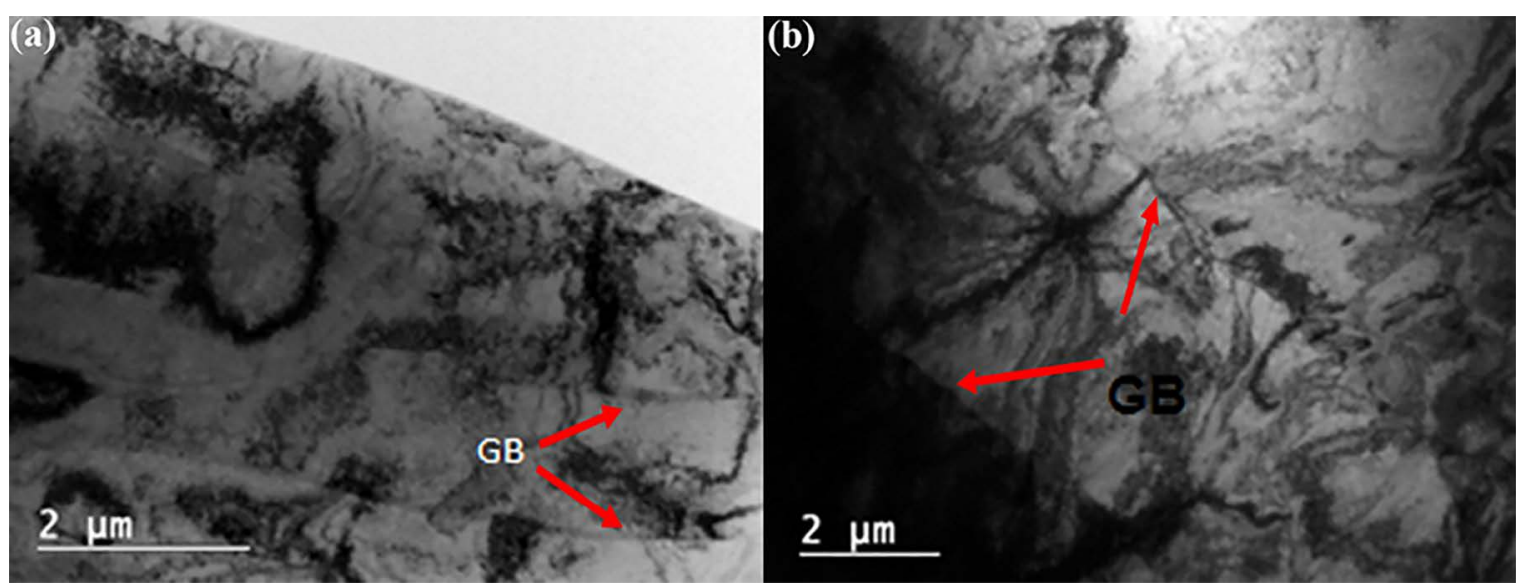

Figure 5. (a,b) Micrographs obtained in bright field in TEM corresponding to microstructure of the WR $80 \%$ at $600^{\circ} \mathrm{C}$. (a,b) Formation of cell blocks along with dense dislocations walls, $(\mathrm{a}, \mathrm{b})$ original high angle grain boundary between ferrite and austenite indicated by arrows. 


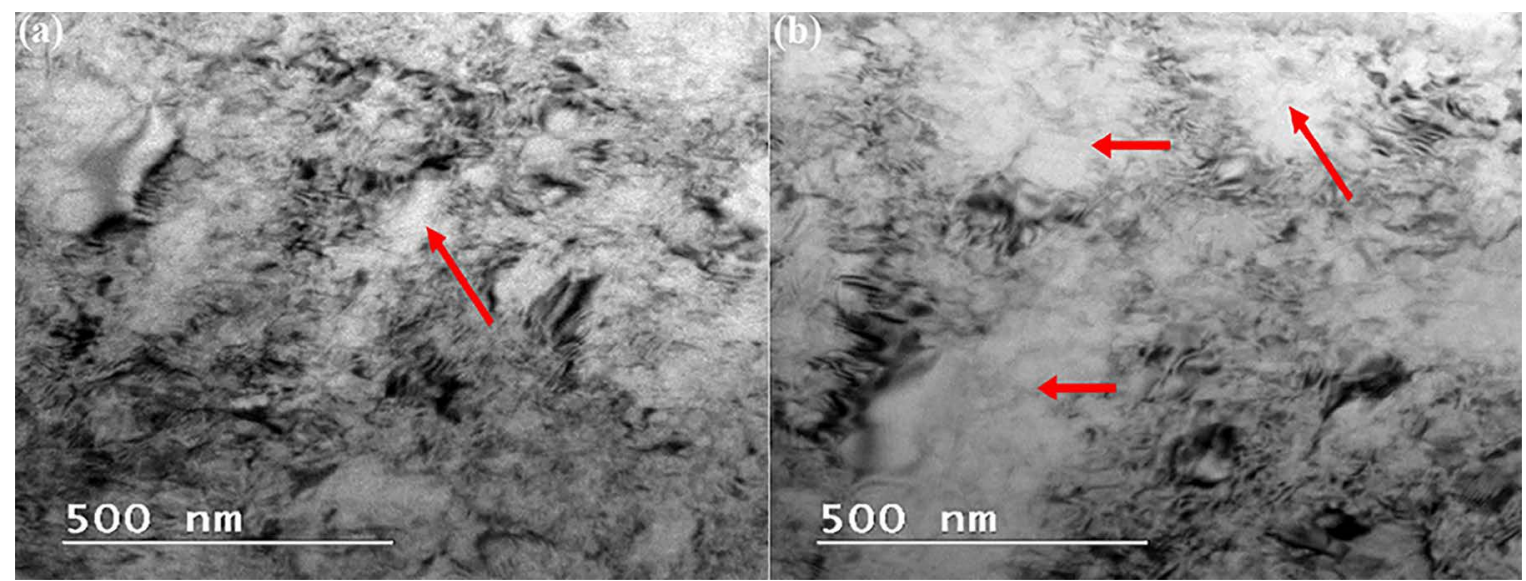

Figure 6. Micrographs obtained in the TEM in bright field mode of the WR $80 \%$, dense dislocations walls and (a) poorly defined channels in ferrite, (b) central areas of deformed austenite and ferrite grains with less dislocations, more clear areas, indicating recovery process (point out by arrows).

The deformation in the austenite occurs due to the slip of dislocations and intense twining, facilitated by the low stacking fault energy of this phase. A preferred orientation is observed when both mechanisms occur simultaneously. Ferrite, in contrast, has a crystalline BCC system with high stacking fault energy. Since the probability of generating the stacking faults is very small, the screw dislocations can cross-slip, allowing accommodating large deformations with a small change in the orientation of their crystallographic structure. Thus, the grain refinement is achieved by the successive subdivision of the dislocations walls ${ }^{26-29}$.

Figure 7 represent the engineering stress-strain curves for AR and WR samples. A significant increase of the mechanical strength properties and the respective ductility reduction (total elongation) is observed. In turn, the microhardness Vickers (Table 2) of the warm rolled samples converges to an average value of $408 \mathrm{HV}$, well above the received conditions of the steel. In this way, it is possible to conclude that the warm rolling route of the DSS used here is suitable to produce a high strength microstructure. By their turn, the warm rolled condition can double the yield and tensile strength, achieving a reasonable ductility level, around $10 \%$ of the total elongation (Figure 7).

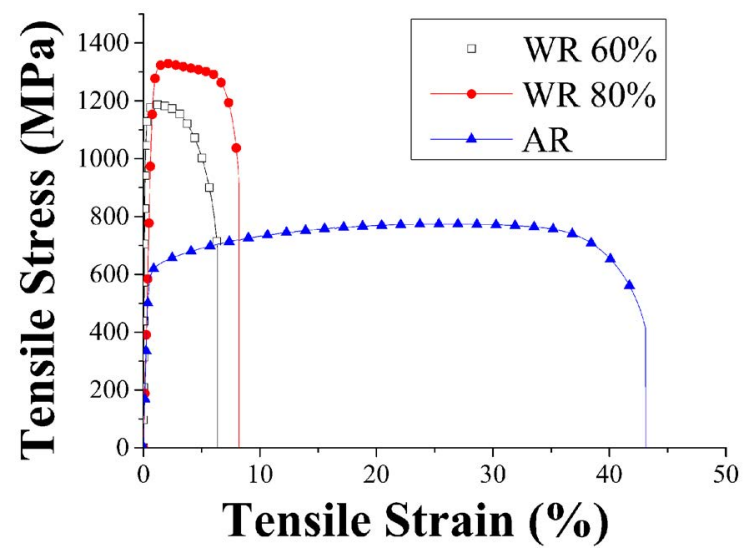

Figure 7. Engineering stress-strain curves for AR, WR $60 \%$ and WR $80 \%$ samples.
Table 2. HV - Microhardness Vickers (2,97 N)

\begin{tabular}{cc}
\hline & HV \\
AR & $281 \pm 12$ \\
WR 60\% & $410 \pm 9$ \\
WR 80\% & $405 \pm 14$ \\
\hline
\end{tabular}

This behaviour has been observed by other authors ${ }^{5,11}$ that used a DSS with $24.5 \% \mathrm{Cr}$ and $10.5 \% \mathrm{Ni}$ for warm rolling, but there is not a detailed description about substructures formed.

This level of mechanical strength was reached in an experiment that involved the hydrostatic extrusion process with a true deformation of 1.4 in DSS steel with $0.3 \%$ $\mathrm{C} ; 22 \% \mathrm{Cr} ; 5 \% \mathrm{Ni}$ and $3.0 \% \mathrm{Mo}$. In this case, the tensile strength of $1370 \mathrm{MPa}$ was reached, but with only $5 \%$ of total elongation ${ }^{26}$.

The diffraction patterns of AR, WR $60 \%$ and WR $80 \%$ are shown in Figure $8(\mathrm{a}-\mathrm{c})$, respectively. The quantitative phase volume fraction results are summarized in Table 3 . They confirmed the presence of austenite and ferrite in the samples structure.

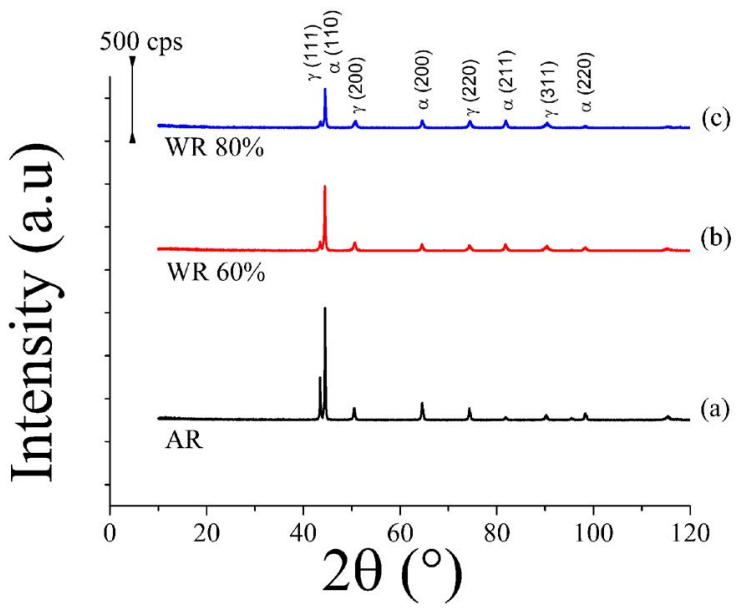

Figure 8. Diffraction patterns of (a) AR, (b) WR $60 \%$ and (c) WR $80 \%$ samples. 
Table 3. Relative phase amounts calculated by x-ray diffraction

\begin{tabular}{ccc}
\hline Condition & \% Ferrite $(\alpha)$ & $\%$ Austenite $(\gamma)$ \\
\hline AR & 35 & 65 \\
WR 60\% & 32 & 68 \\
WR 80\% & 40 & 60 \\
\hline
\end{tabular}

The volume fraction of $\alpha$-ferrite in the warm rolled samples did not chanco AR condition (Table 3 ). No deleterious phase, such as $\sigma, \chi$, carbides or nitrites were observed in the diffraction patterns (Fig. 8a-c).

Microhardness measurements reveal that the thermomechanical process increases the steel hardness and it was demonstrated that the major contributing factor is the generation of dislocation substructure leading to a grain division in cell blocks and frontiers formed by HDDW. Nevertheless, no significantly hardness difference between WR 60\% and WR 80\% was observed (Table 2). A detailed examination using TEM micrographs, Figures 4, 5 and 6, cannot establish quantitative differences in dislocations density for warm rolled samples. However, the ductility of WR $80 \%$ sample is greater than WR $60 \%$ sample as illustrated in Figure 7. One reason for this behaviour is due to the high number of interpass annealing for WR $80 \%$ sample (16 for WR $80 \%$ and 9 for WR 60\%), i.e. this sample spent more time in the furnace (at $600^{\circ} \mathrm{C}$ ) in order to apply the total reduction. This processing provides a more intense recovery of dislocations and a small increase in ductility for this sample. This behaviour could be related to the corrosion resistance, as will be shown.

The results of electrochemical impedance provide information related to the electrochemical process that occurs in the system under study. The interpretation of the impedance data was done through the analysis of equivalent electrical circuits. In this work the equivalent circuit constituted by the arrangement $\left(\mathrm{R}_{\mathrm{s}}\left(\mathrm{CPE} \| \mathrm{R}_{\mathrm{ct}}\right)\right.$ ) was used, in which the element $R_{s}$ is the resistance of the solution, $R_{c t}$ is the charge transfer resistance through the passive film and at the interface with solution and CPE is the constant phase element with parameter Q describing the CPE magnitude and $n$ the capacitive dispersion. Figures 9 and 10 show the Nyquist and Bode diagram, respectively, for AR and WR samples.

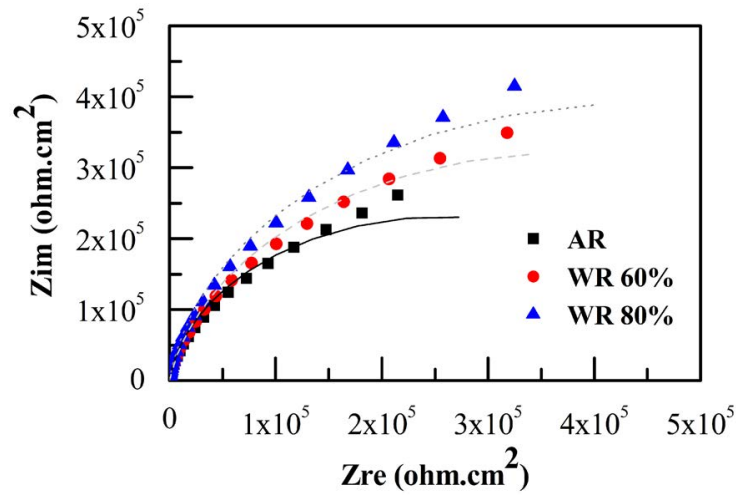

Figure 9. Nyquist diagram.

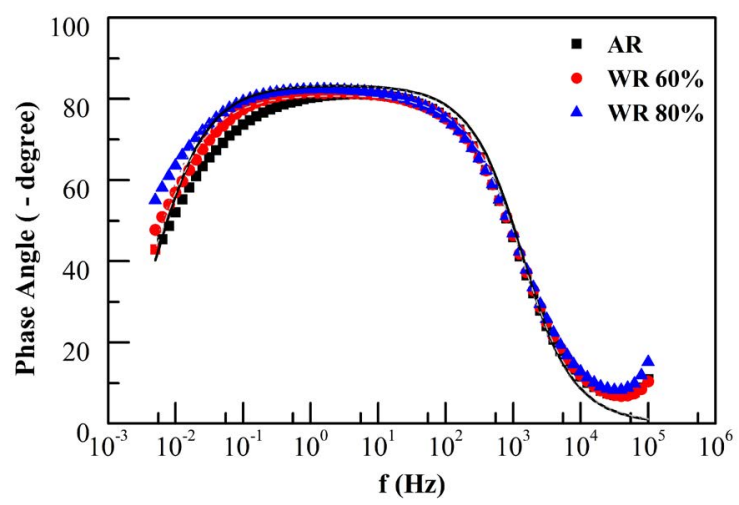

Figure 10. Bode diagram.

The Nyquist diagram shows a difference in the diameter of the semicircle obtained for the as received steel and the warm rolled samples, indicating a slower corrosive process for the rolled samples. The electrochemical properties of the corrosive system, including the solution resistance, charge transfer resistance and CPE parameters, $n$ and $\mathrm{Q}$, are shown in Table 4. The $\mathrm{R}_{\mathrm{ct}}$ was lower for 2205 as received sample than that of warm rolled. Regarding the rolled samples, the $\mathrm{R}_{\mathrm{ct}}$ increased with increasing deformation. According to Fattah-Alhosseini and Vafaeian ${ }^{30}$ the change in the value of $Q$ for the passive film is a sign of change in the thickness of the passive film formed. The value of $Q$ decreased with the rolling process, indicating that the thermomechanical treatment led to thicker passive film under these conditions.

Table 4. Fitting parameters for experimental EIS data

\begin{tabular}{|c|c|c|c|c|c|c|}
\hline & \multicolumn{2}{|c|}{$\mathrm{AR}$} & \multicolumn{2}{|c|}{ WR $60 \%$} & \multicolumn{2}{|c|}{ WR $80 \%$} \\
\hline & Value & Deviation & Value & Deviation & Value & Deviation \\
\hline $\mathrm{R}_{\mathrm{s}}\left(\mathbf{\Omega} \cdot \mathrm{cm}^{2}\right)$ & 6.42 & 1.25 & 8.56 & 0.48 & 8.10 & 0.44 \\
\hline $\mathrm{R}_{\mathrm{ct}}\left(\mathrm{k} \boldsymbol{\Omega} . \mathrm{cm}^{2}\right)$ & 500 & 82 & 734 & 98 & 913 & 184 \\
\hline$Q\left(\mu \Omega^{-1} \cdot \mathrm{cm}^{-2} \cdot \mathbf{s}^{\mathrm{n}}\right)$ & 42.6 & 3.7 & 33.9 & 0.8 & 34.5 & 4.3 \\
\hline $\mathbf{n}$ & 0.901 & 0.023 & 0.899 & 0.029 & 0.913 & 0.013 \\
\hline
\end{tabular}


It is well known that a thicker layer provides a more effective protection against corrosive medium, for a similar chemical composition.

Figure 11 shows the cyclic potentiodynamic polarization curves obtained for samples of 2205 steel AR and WR 60\% and WR $80 \%$. The mean values of pitting potentials $\left(\mathrm{E}_{\mathrm{pit}}\right)$ and repassivation potentials $\left(\mathrm{E}_{\mathrm{prot}}\right)$ and the respective standard deviations are summarized in Table 5.

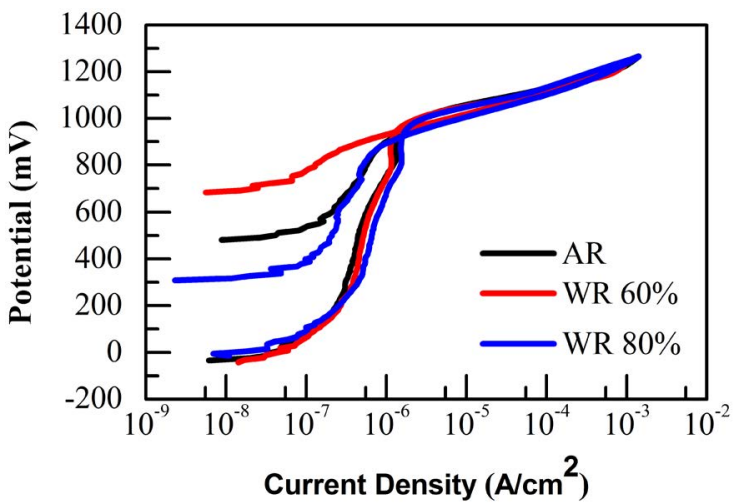

Figure 11. Cyclic potentiodynamic polarization curves.
Figure 11 shows that the samples have a high and similar pitting potential $\left(\mathrm{E}_{\mathrm{pit}}\right)$ and a wide region of passivation that can be attributed to the significant content of $\mathrm{Mo}$ and $\mathrm{Ni}$ present in the steel. These elements play a fundamental role in the stabilization of the passive film formed on the surface of these alloys ${ }^{31,32}$. The $\mathrm{E}_{\mathrm{pit}}$ obtained for all samples was close to $1000 \mathrm{mV}$ and its precise value can be disguised by the oxygen evolution, however, all samples exhibited pits after the polarization test (Figure 12) ${ }^{33}$. The passivation currents for all samples are in the same range, around $10^{-6} \mathrm{~A} / \mathrm{cm}^{2}$. The repassivation potentials during cathodic polarization were also similar. This polarization (Figure 11) showed a small positive hysteresis and a high repassivation potential, indicating that the material has repassivation capacity in $3.5 \% \mathrm{~m} / \mathrm{v}$ sodium chloride solution.

The similar $\mathrm{E}_{\mathrm{pit}}$ values obtained for all samples suggest that the thermomechanical treatment employed did not significantly influence the pitting corrosion resistance of 2205 DSS, but this characteristic pitting potential is not the only parameter that should be used to evaluate the resistance to pitting corrosion. Another important parameter is pitting density (number of pits per area) ${ }^{34}$.

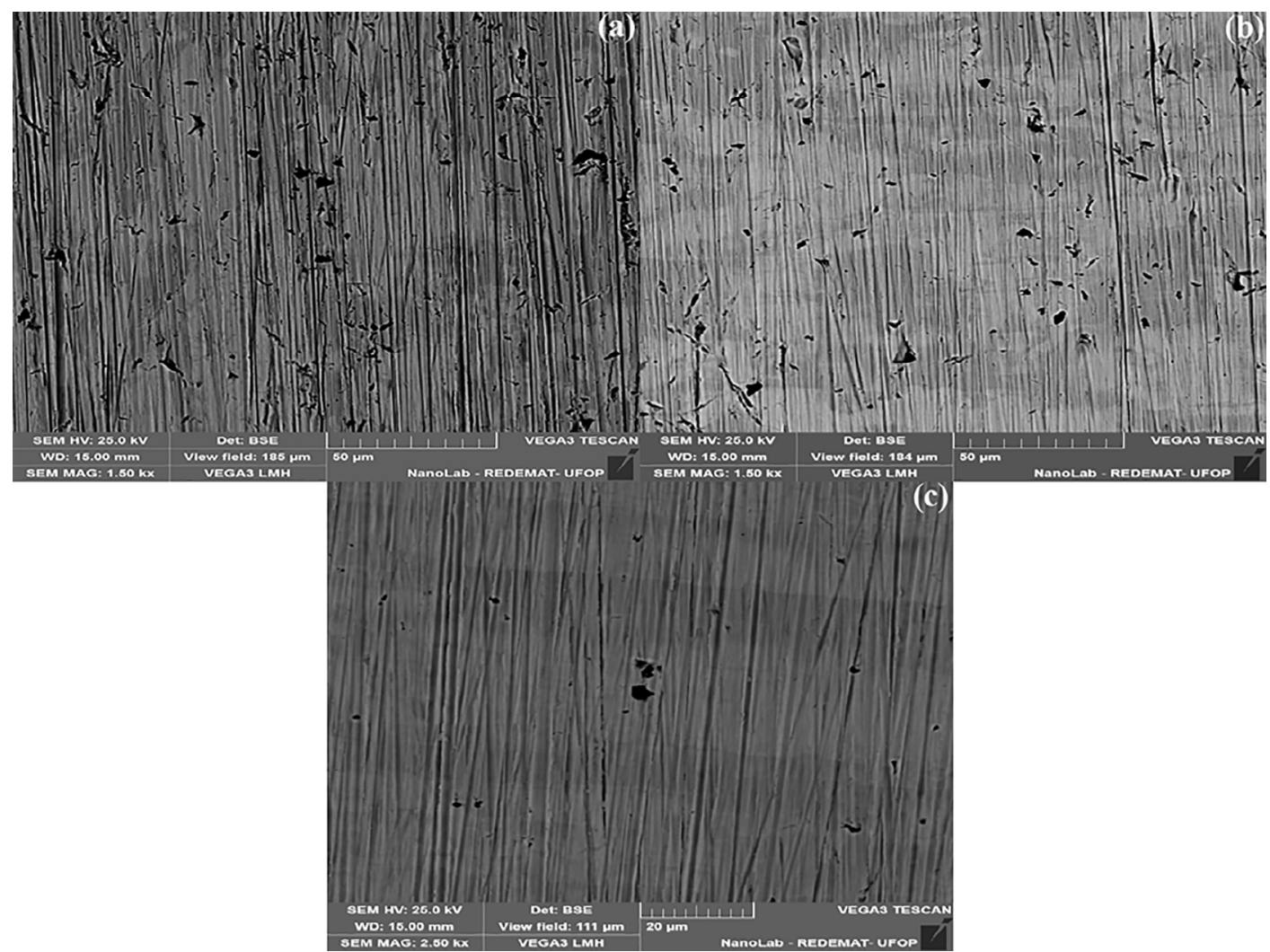

Figure 12. Pits distribution after the polarization tests: (a) AR, (b) WR 60\% and (c) WR 80\%.

Table 5. CPP experimental results

\begin{tabular}{ccccc}
\hline Sample & $\mathrm{E}_{\text {pit }}(\mathrm{mV})$ & Deviation $(\mathrm{mV})$ & $\mathrm{E}_{\text {prot }}(\mathrm{mV})$ & Deviation $(\mathrm{mV})$ \\
\hline AR & 987 & 10 & 912 & 39 \\
WR 60\% & 994 & 14 & 937 & 4 \\
WR 80\% & 1010 & 26 & 921 & 30 \\
\hline
\end{tabular}


The samples were observed using SEM after the electrochemical test (Figure 12). Small pits were found in both austenite and ferrite phases, showing equivalent corrosion resistance for both phases before and after warm rolling. The corrosion by pitting in saline solution confirmed by Figure 12 is consistent with dislocation density reduction due to recovery of the warm rolled samples as discussed before. The pitting corrosion in saline solution was more intense for AR sample, followed by WR 60\% and WR $80 \%$ samples, as indicated by the increase in the number of pits observed in Figure 12 (a-c).

As exposed by Sarlak et al. ${ }^{35}$, microstructural features such as ferrite/austenite ratio and the presence of deleterious phases are some of the detrimental factors on the corrosion behaviour of DSS. The XRD analysis show no significantly difference of ferrite/austenite ratio between the warm rolled and as-received conditions (Table 3 ) and, besides that, no deleterious phase were found before and after the thermomechanical treatment. The relation between pitting corrosion resistance and phase volume fraction of UNS S32205 duplex stainless steel was also investigated by Ha et al. ${ }^{36}$. According to their results, the highest pitting potential was observed in the sample comprising $57 \%$ volume fraction of ferrite, and it decreased with increase in the phase imbalance. This fact could explain the similar pit nucleation resistance $\left(\mathrm{E}_{\text {pit }}-\mathrm{E}_{\text {corr }}\right){ }^{15}$ among AR and WR samples, since they showed, approximately, the same ferrite/ austenite ratio (Table 3). On the other hand, the sites for preferential pitting nucleation in UNS S31803 duplex stainless steel was observed by Jiang et $a l .{ }^{37}$ and they founded that is not directly determined by the ferrite and austenite phase ratio, being mainly controlled by both microstructure and composition of the two single phases.

Some important changes in the microstructure of austenitic stainless steel are promoted by the cold working ${ }^{38}$. Some previous work ${ }^{17,39,40}$ has shown a decreasing for pitting potential with certain levels of cold rolling (below $60 \%$ ). However, in the present work the results have showed that warm deformation up to 60 and $80 \%$ did not impaired the corrosion resistance. In this direction, similar behaviour was described by Moura et al. ${ }^{9}$ in cold rolled 2205 tested in $3.5 \% \mathrm{NaCl}$ solution and by Ramirez et al..$^{40}$, which $70 \%$ of cold deformation of austenitic stainless steel resulted in a similar corrosion resistance of samples without deformation.

In some studies, the pitting susceptibility has been also associated to steel texture (crystallographic grain orientation). Venegas et al. ${ }^{17}$ founded for high strength low alloy steel the highest pitting corrosion resistance at $\{110\}$ ND texture fibre. The resistance of the $\{\mathrm{hkl}\} \mathrm{ND}$ texture fibres to pitting corrosion in their studied steel was first assumed and then experimentally observed to decreases in the following order: $\{110\} N D ;\{200\} N D>\{222\} N D>\{112\} N D>$ Random.
Ravi Kumar et al. ${ }^{18}$ reported the adverse effect of the rolling tensile residual stress on passivation and prepassivation characteristics of an austenitic stainless steel. According to them, this effect appears to be nullified by the beneficial crystallographic orientation at higher reductions. In their ${ }^{41}$ study, austenite (f.c.c.) and $\alpha$ 'martensite (b.c.c.) phases offer high-packing density crystal faces of type $\{110\}$ of FCC and $\{111\}$, as well as $\{001\}$ of b.c.c. to the solution attack. For higher reductions, passivation and prepassivation characteristics are improved by the crystallographic orientation developed in the samples. Crystallographic texture seems to play an important role to alter pitting mechanism. Either by reducing favourable sites for corrosion attack or by promoting the formation of Cr-rich passive film on the rolling surface. The authors were able to make a correlation of individual metallurgical changes, i.e., texture, residual stresses from cold worked or warm worked as $\alpha^{\prime}$-martensite formation, and dislocation density, with corrosion resistance by sequential removal of stress and second phase by annealing treatment ${ }^{18}$.

Figure 13 illustrate ODF (Orientation Distribution Function) for $\varphi_{2}=45^{\circ}$ of as received and warm rolled samples for ferrite and austenite phase. The strong components, $\alpha$-fibre appear and rotate cube, are evidenced for ferrite, Fig. $13(a-c)$. By their turn, brass is the strongest $(\{110\}<112>)$ component that appear for austenite, Fig. 13(d-f). The microtexture represented in the ODF sections (Fig. 13) were measure from the ND-RD areas of the thickness centre layer. To emphasize the influence of crystal orientation on corrosion behaviour, samples removed from rolling plane, i.e., the plane that contain the $\mathrm{RD}$ and $\mathrm{TD}$ directions, were also submitted to EBSD analysis. The results are illustrated in Fig. 14(a-d).

The reduction of intensity in Fig 13 (a-d) is due to the working hardening of the warm rolled microstructure. The increasing in crystal defects, such as dislocation, decreases the intensity of backscattered electrons that will form the Kikuchi patterns. It seems that this difference is too small to affect the pitting potential.

Although Lillard ${ }^{41}$ related that the plane (110) is easier to nucleate pits as compared to others low indices planes ${ }^{41}$, some other authors have related a different behaviour ${ }^{17,42,44}$. Results presented by Shahryari et al..$^{44}$ indicate that the pitting corrosion susceptibility of the grains depends on the crystallographic planes, proving the anisotropic nature of pitting initiation on the surface. According to their results, the planar orientations $\{111\}$ and $\{100\}$ have the highest resistance to pitting corrosion ${ }^{44}$. The texture shown in Fig. $14(\mathrm{~b}, \mathrm{c})$ corresponds to the planes $\{101\},\{100\}$ and $\{111\}$ with more intensity for both phases, austenite and ferrite, in agreement with Shahryari et al. results ${ }^{44}$. 


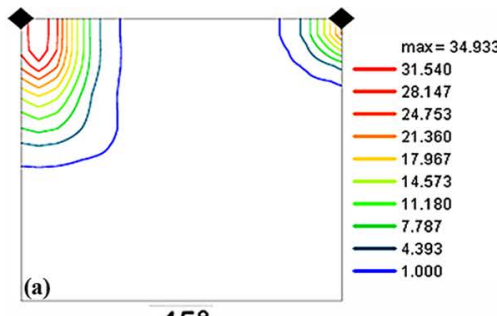

$45^{\circ}$

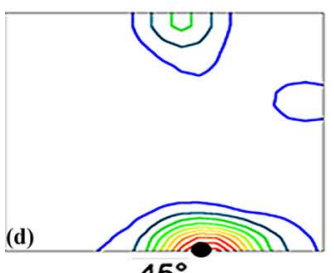

$45^{\circ}$

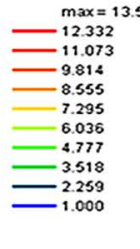

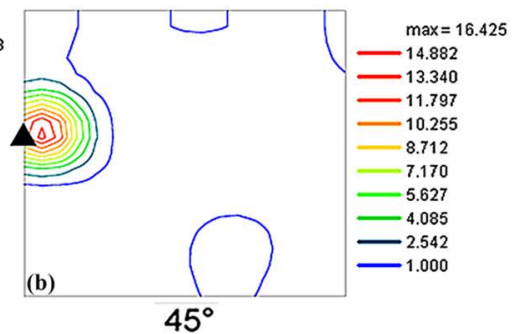

$45^{\circ}$

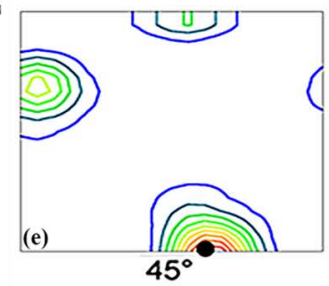

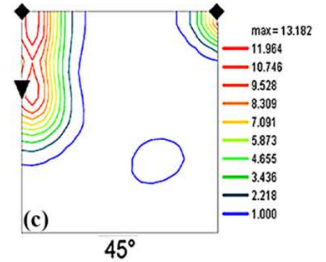

$\bullet\{001\}<110>$

$\wedge\{112\}<110>$

v $\{113\}<110>$

Figure 13. Illustration of the $\varphi_{2}=45^{\circ}$ sections of the $\operatorname{ODF}(\mathrm{a}, \mathrm{b}, \mathrm{c})$ for ferrite and $(\mathrm{e}, \mathrm{d}, \mathrm{f})$ for austenite determined in the centre layer of the samples: (a,d) AR, (b,e) WR $60 \%$ and (c,f) WR $80 \%$.

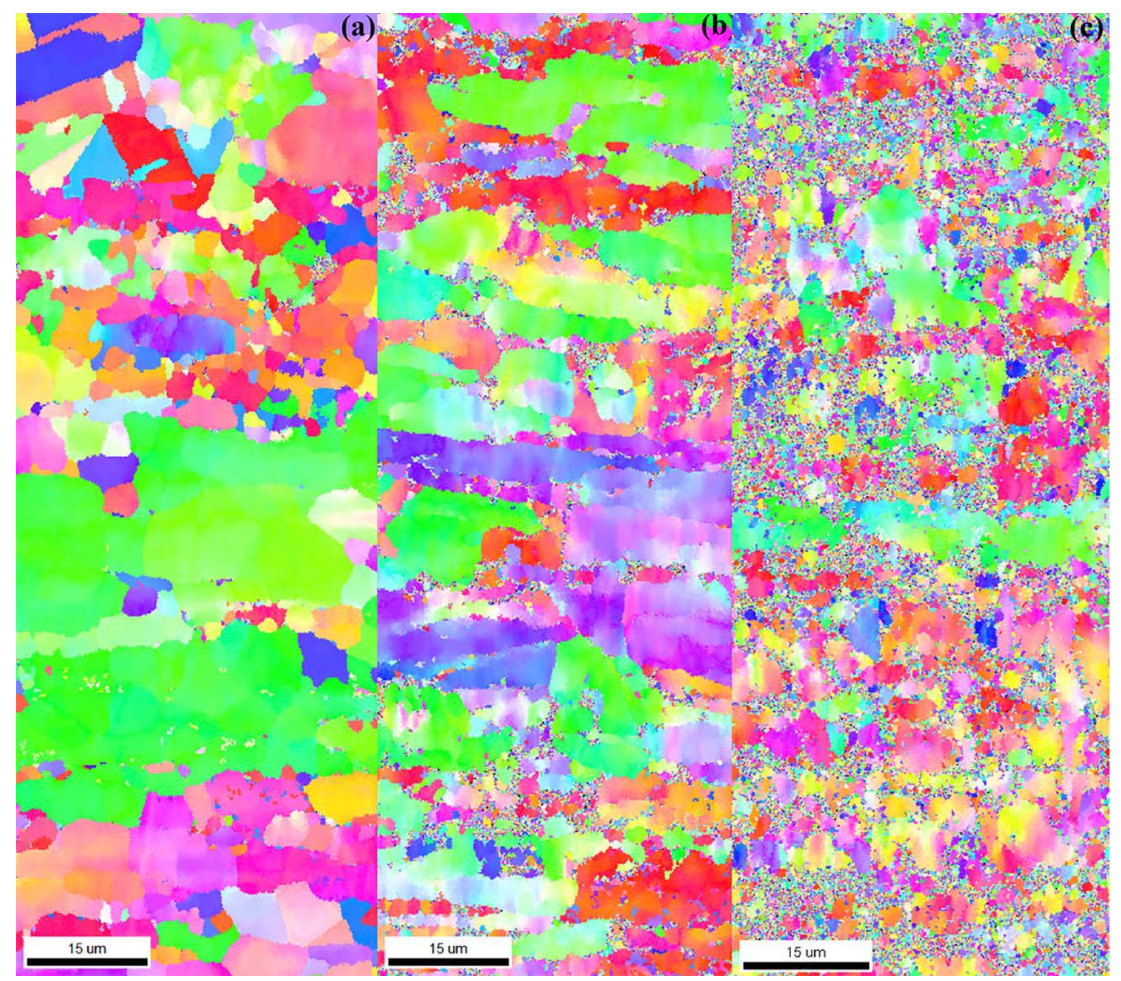

(d)

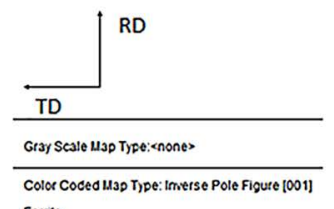

Ferrtie

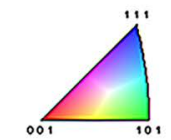

Austerise

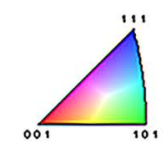

Boundaries: enone>

Figure 14. Inverse pole figures obtained in rolling plane of the samples, i.e., the plane that contain the RD and TD directions. (a) AR(b) WR 60\%, and (c) WR 80\%, (d) IPF triangle.

Moura et al. ${ }^{9}$ reported that in their work the comparison of samples of DSS 31803, cold rolled in $\varepsilon=0.51$ and $\varepsilon=1.61$, shows that cold deformation up to $\varepsilon=1.61 \mathrm{did}$ not affect the pitting potential of the DSS in $3.5 \% \mathrm{NaCl}$ solution, even when some $\alpha$ '-martensite was generated. In this direction, Balusamy et al. $^{45}$ applying surface mechanical attrition treatment (SMAT) enabled surface nanocrystallization, promoted passive film formation and increased the corrosion resistance of AISI 409 stainless steel in $0.6 \mathrm{M} \mathrm{NaCl}$.
They conclude that the corrosion resistance depends on surface nanocrystallization, extent of grain refinement and decrease in grain size and, increase in microstrain and defect density, induced during treatment ${ }^{45}$. Some of these important events happen during warm rolling, as grain refinement, see Fig. 14 (b,c) and linear crystal defects generation, dislocations, see Fig. 3 to 6.

Zheng et al. ${ }^{43}$ found little difference for thickness and composition of the passive film formed on both as-received and nanocrystalline 304 stainless steel in $0.5 \mathrm{M} \mathrm{H}_{2} \mathrm{SO}_{4}$. 
However, grain refinement could improve the chromium diffusion and promoted to the forming of compact passive film due to the presence of more grain boundaries ${ }^{4}$. Summarizing, the warm rolling has the potential to enhance the passive film formation by introducing a substructure that containing arrangements of tangles dislocations and subgrains that enable the atoms diffusion, mainly $\mathrm{Cr}$ atoms, as proposed by Jinlong et al. ${ }^{4}$. The EIS results (Table 4) confirm this potential of the warm rolling in enhance the passive film formation.

\section{Conclusions}

The study showed the tensile strength reached 1185 $\mathrm{MPa}$ and $1328 \mathrm{MPa}$, after warm rolling for 60 and $80 \%$, respectively. In steel as supplied, hot rolled, the tensile strength was $774 \mathrm{MPa}$. The hardness of the steel in this condition was $281 \mathrm{HV}$ and around $410 \mathrm{HV}$ for both warm rolling conditions. Regarding the microstructure it can be said that this was characterized by the intense formation of tangles and forests of dislocations. In addition, the comparison of the mechanical behaviour with the steel in the condition AR revealed that the warm work raised the mechanical strength level between 65 to $72 \%$.

Regarding the corrosion results, it was possible to observe the $\mathrm{R}_{c t}$ value was lower for as received sample than that of warm rolled samples. Among the warm rolled samples, the increasing in deformation from $60 \%$ to $80 \%$ in thickness reduction resulted in higher $\mathrm{R}_{\mathrm{ct}}$ value for UNS S32205 steel. Besides that, the samples had excellent corrosion resistance in $3.5 \% \mathrm{NaCl}$ solution and showed repassivation capacity in medium containing chlorides. Lastly, the microtexture measurement of the steel was comprised with the results of the potentiodynamic polarization and EIS measurements, showing that the passivation behaviour improves after higher reductions during warm rolling.

\section{Acknowledgements}

The authors are grateful to Aperam South America for the steel samples supply. Also thank the CAPES-PROEX-PPGEM/ UFMG, CNPq and FAPEMIG for the student fellowship and financial support. Thanks to Centro de Microscopia - UFMG for transmission electron microscopy examination.

\section{References}

1. Michalska J, Sozanska M. Qualitative and quantitative analysis of $\sigma$ and $\chi$ phases in 2205 duplex stainless steels. Materials Characterization. 2006;56(4-5):355-362.

2. Escobar JD, Velásquez E, Santos TFA, Ramirez AJ, López D. Improvement of cavitation erosion resistance of a duplex stainless steel through friction stir processing (FSP). Wear. 2013;297(1-2):998-1005.
3. Sicupira DC, Cardoso Junior R, Bracarense AQ, Frankel GS, Lins VFC. Cyclic Polarization Study of Thick Welded Joints of Lean Duplex Stainless Steel for Application in Biodiesel Industry. Materials Research. 2017;20(1):161-167.

4. Lv J, Liang T, Wang C, Dong L. Effect of ultrafine grain on tensile behaviour and corrosion resistance of the duplex stainless steel. Materials Science and Engineering: $C$. 2016;62:558-563.

5. Ahmed MZ, Bhattacharjee PP. Microstructure, Texture, and Tensile Properties of a Severely Warm-Rolled and Annealed Duplex Stainless Steel. Steel Research International. 2016;87(4):472-483.

6. Chen L, Tan H, Wang Z, Li J, Jiang Y. Influence of cooling rate on microstructure evolution and pitting corrosion resistance in the simulated heat-affected zone of 2304 duplex stainless steel. Corrosion Science. 2012;58:168-174.

7. Stergiou V, Papadimitriou GD. Effect of an electron beam surface treatment on the microstructure and mechanical properties of SAF 2205 joints produced with electron beam welding. Journal of Materials Science. 2012;47(5):2110-2121.

8. Gholami M, Hoseinpoor M, Moayed MH. A statistical study on the effect of annealing temperature on pitting corrosion resistance of 2205 duplex stainless steel. Corrosion Science. 2015;94:156-164.

9. Moura VS, Lima LD, Pardal JM, Kina AY, Corte RRA, Tavares SSM. Influence of the microstructure on the corrosion resistance of the duplex stainless steel UNS S31803. Materials Characterization. 2008;59(8):1127-1132.

10. Lenard JG. Primer on Flat Rolling. Oxford: Elsevier; 2013.

11. Bhattacharjee PP, Zaid M, Sathiaraj GD, Bhadak B. Evolution of Microstructure and Texture During Warm Rolling of a Duplex Steel. Metallurgical and Materials Transactions A. 2014;45(4):2180-2191.

12. Ryś J, Ratuszek W, Witkowska M. Rolling Texture Differences in Duplex Steels with Strong and Random Initial Orientations. Solid State Phenomena. 2007;130:57-62.

13. Ardila MAN, Labiapari WS, de Mello JDB. The Influence of Crystallographic Texture and Niobium Stabilisation on the Corrosion Resistance of Ferritic Stainless Steel. Materials Research. 2017;20(3):576-583.

14. Farnoush H, Momeni A, Dehghani K, Mohandesi JA, Keshmiri H. Hot deformation characteristics of 2205 duplex stainless steel based on the behavior of constituent phases. Materials \& Design. 2010;31(1):220-226.

15. Zhang Z, Zhao H, Zhang H, Yu Z, Hu J, He L, et al. Effect of isothermal aging on the pitting corrosion resistance of UNS S82441 duplex stainless steel based on electrochemical detection. Corrosion Science. 2015;93:120-125.

16. Lv J, Guo W, Liang T. The effect of pre-deformation on corrosion resistance of the passive film formed on 2205 duplex stainless steel. Journal of Alloys and Compounds. 2016; 686:176-183. 
17. Venegas V, Caleyo F, Vázquez LE, Baudin T, Hallen JM. On the Influence of Crystallographic Texture on Pitting Corrosion in Pipeline Steels. International Journal of Electrochemical Science. 2015;10:3539-3552.

18. Kumar BR, Singh R, Mahato B, De PK, Bandyopadhyay NR, Bhattacharya DK. Effect of texture on corrosion behaviour of AISI 304L stainless steel. Materials Characterization. 2005;54(2):141-147.

19. Keichel J, Foct J, Gottstein G. Deformation and Annealing Behaviour of Nitrogen Alloyed Duplex Stainless Steels. Part II: Annealing. ISIJ International. 2003;43(11):1788-1794.

20. Cizek P. The microstructure evolution and softening processes during high-temperature deformation of a $21 \mathrm{Cr}-10 \mathrm{Ni}-3 \mathrm{Mo}$ duplex stainless steel. Acta Materialia. 2016;106:129-143.

21. Mateo A, Gironès A, Keichel J, Llanes L, Akdut N, Anglada M. Cyclic deformation behaviour of superduplex stainless steels. Materials Science and Engineering: A. 2001;314(1-2):176-185.

22. Yu D, Yu W, Chen G, Jin F, Chen X. Role of dynamic strain aging in the tensile property, cyclic deformation and fatigue behavior of Z2CND18.12N stainless steel between $293 \mathrm{~K}$ and $723 \mathrm{~K}$. Materials Science and Engineering: A. 2012;558:730-736.

23. Hong SG, Lee SB. Mechanism of dynamic strain aging and characterization of its effect on the low-cycle fatigue behaviour in type 316L stainless steel. Journal of Nuclear Materials. 2005;340(2-3):307-314.

24. Belyakov A, Kimura Y, Tsuzaki K. Microstructure evolution in dual-phase stainless steel during severe deformation. Acta Materialia. 2006;54(9):2521-2532.

25. Chen L, Yuan FP, Jiang P, Wu XL. Mechanical properties and nanostructures in a duplex stainless steel subjected to equal channel angular pressing. Materials Science and Engineering: A. 2012;551:154-159.

26. Maj P, Adamczyk-Cieślak B, Mizera J, Pachla W, Kurzydłowski KJ. Microstructure and mechanical properties of duplex stainless steel subjected to hydrostatic extrusion. Materials Characterization. 2014;93:110-118.

27. Padilha AF, Plaut RL, Rios PR. Annealing of Cold-worked Austenitic Stainless Steels. ISIJ International. 2003;43(2):135143.

28. Patra S, Ghosh A, Singhal LK, Podder AS, Sood J, Kumar $\mathrm{V}$, et al. Hot Deformation Behaviour of As-Cast 2101 Grade Lean Duplex Stainless Steel and the Associated Changes in Microstructure and Crystallographic Texture. Metallurgical Materials Transactions A. 2017;48(1):294-313.

29. Cao Y, Wang YB, An XH, Liao XZ, Kawasaki M, Ringer SP, et al. Concurrent microstructural evolution of ferrite and austenite in a duplex stainless steel processed by high-pressure torsion. Acta Materialia. 2014;63:16-29.

30. Fattah-alhosseini A, Vafaeian S. Comparison of electrochemical behavior between coarse-grained and fine-grained AISI 430 ferritic stainless steel by Mott-Schottky analysis and EIS measurements. Journal of Alloys and Compounds. 2015;639:301-307.
31. BenSalah M, Sabot R, Triki E, Dhouibi L, Refait P, Jeannin M. Passivity of Sanicro28 (UNS N-08028) stainless steel in polluted phosphoric acid at different temperatures studied by electrochemical impedance spectroscopy and Mott-Schottky analysis. Corrosion Science. 2014;86:61-70.

32. Blasco-Tamarit E, Igual-MuñozA, García Antón J, García-García D. Effect of aqueous $\mathrm{LiBr}$ solutions on the corrosion resistance and galvanic corrosion of an austenitic stainless steel in its welded and non-welded condition. Corrosion Science. 2006;48(4):863-886.

33. Sriram R, Tromans D. Pitting Corrosion of Duplex Stainless Steels. Corrosion. 1989;45(10):804-810.

34. McCafferty E. Introduction to Corrosion Science. New York: Springer; 2010.

35. Sarlak H, Atapour M, Esmailzadeh M. Corrosion behaviour of friction stir welded lean duplex stainless steel. Materials \& Design (1980-2015). 2015;66(Pt A):209-2016.

36. Ha HY, Jang MH, Lee TH, Moon J. Interpretation of the relation between ferrite fraction and pitting corrosion resistance of commercial 2205 duplex stainless steel. Corrosion Science. 2014;89:154-162.

37. Jiang Y, Sun T, Li J, Xu J. Evaluation of Pitting Behaviour on Solution Treated Duplex Stainless Steel UNS S31803. Journal of Materials Science \&Technology. 2014;30(2):179-183.

38. Barbucci A, Delucchi M, Panizza M, Sacco M, Cerisola G. Electrochemical and corrosion behaviour of cold rolled AISI 301 in $1 \mathrm{M} \mathrm{H}_{2} \mathrm{SO}_{4}$. Journal of Alloys and Compounds. 2001;317318:607-611.

39. Fu Y, Wu X, Han E, Ke W, Yang K, Jiang Z. Influence of Cold Work on Pitting Corrosion Behaviour of a High Nitrogen Stainless Steel. Journal of the Electrochemical Society. 2008;155(8):C455-C463.

40. Ramirez AH, Ramirez CH, Costa I. Cold Rolling Effect on the Microstructure and Pitting Resistance of the NBR ISO 5832-1 Austenitic Stainless Steel. International Journal of Electrochemical Science. 2013;8(12):12801-12815.

41. Lillard RS. Relationships between Pitting Corrosion and Crystallographic Orientation, An Historical Perspective. In: Proceedings of Corrosion science: A retrospective and current status in honor of Robert P Frankenthal; 2002 May 12-17; Philadelphia, PA, USA. p. 334-343.

42. 41. Vignal V, Ba D, Zhang H, Herbst F, Le Manchet S. Influence of the grain orientation spread on the pitting corrosion resistance of duplex stainless steels using electron backscatter diffraction and critical pitting temperature test at the microscale. Corrosion Science. 2013;68:275-278.

43. Zheng ZJ, Gao Y, Gui Y, Zhu M. Corrosion behaviour of nanocrystalline 304 stainless steel prepared by equal channel angular pressing. Corrosion Science. 2012;54:60-67.

44. Shahryari A, Szpunar JA, Omanovic S. The influence of crystallographic orientation distribution on 316LVM stainless steel pitting behavior. Corrosion Science. 2009;51(3):677-682.

45. Balusamy T, Kumar S, Narayanan TSNS. Effect of surface nanocrystallization on the corrosion behaviour of AISI 409 stainless steel. Corrosion Science. 2010;52(11):3826-3834. 